\title{
Direct Detection of Fe(II) in Extracellular Polymeric Substances (EPS) at the Mineral-Microbe Interface in Bacterial Pyrite Leaching
}

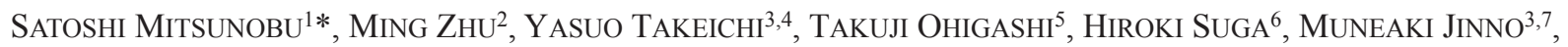 \\ HiroKo MAKITA $^{8}$, MASAHIRO SAKATA ${ }^{2}$, KANTA ONO ${ }^{3,4}, \mathrm{KAZUHIKO} \mathrm{MASE}^{3,4}$, and YOSHIO TAKAHASHI ${ }^{9}$ \\ ${ }^{1}$ Department of Environmental Conservation, Graduate School of Agriculture, Ehime University, Tarumi, Matsuyama 790-8566, \\ Japan; ${ }^{2}$ Graduate Division of Nutritional and Environmental Sciences, University of Shizuoka, Yada, Suruga-ku, Shizuoka \\ 422-8526, Japan; ${ }^{3}$ Institute of Materials Structure Science, High-Energy Accelerator Research Organization (KEK), Oho, Tsukuba, \\ Ibaraki 305-0801, Japan; ${ }^{4}$ The Graduate University for Advanced Studies, 1-1 Oho, Tsukuba 305-0801, Japan; ${ }^{5}$ UVSOR facility, \\ Institute for Molecular Science, Myodaiji, Okazaki 444-8585, Japan; ${ }^{6}$ Department of Earth and Planetary Systems Science, \\ Hiroshima University, Kagamiyama, Higashi-Hiroshima, Hiroshima 739-8526; ${ }^{7}$ Toyama Co. Ltd., 4-13-16 Hibarigaoka, Zama, \\ Kanagawa 252-0002, Japan; ${ }^{8}$ Japan Agency for Marine-Earth Science and Technology (JAMSTEC), Natsushima-cho, Yokosuka, \\ Kanagawa 237-0061, Japan; and ${ }^{9}$ Department of Earth and Planetary Science, The University of Tokyo, Hongo, Bunkyo-ku, Tokyo \\ 113-0033, Japan
}

(Received August 31, 2015-Accepted January 9, 2016-Published online March 5, 2016)

We herein investigated the mechanisms underlying the contact leaching process in pyrite bioleaching by Acidithiobacillus ferrooxidans using scanning transmission X-ray microscopy (STXM)-based C and Fe near edge X-ray absorption fine structure (NEXAFS) analyses. The C NEXAFS analysis directly showed that attached $A$. ferrooxidans produces polysaccharide-abundant extracellular polymeric substances (EPS) at the cell-pyrite interface. Furthermore, by combining the C and Fe NEXAFS results, we detected significant amounts of Fe(II), in addition to Fe(III), in the interfacial EPS at the cell-pyrite interface. A probable explanation for the Fe(II) in detected EPS is the leaching of Fe(II) from the pyrite. The detection of Fe(II) also indicates that $\mathrm{Fe}$ (III) resulting from pyrite oxidation may effectively function as an oxidizing agent for pyrite at the cell-pyrite interface. Thus, our results imply that a key role of Fe(III) in EPS, in addition to its previously described role in the electrostatic attachment of the cell to pyrite, is enhancing pyrite dissolution.

Key words: Bacterial mineral leaching, pyrite, chemical speciation, X-ray microscopy

Bioleaching is a mineral leaching process performed by various biological metabolic pathways $(29,30)$. The microbial bioleaching of metal sulfides has been used as a low-cost engineering process to extract metals from sulfidic ores, particularly low-grade ores, including pyrite $\left(\mathrm{FeS}_{2}\right)$ and chalcopyrite $\left(\mathrm{CuFeS}_{2}\right)(22,29,30)$. The microbial bioleaching of metal sulfide also contributes to the formation of environmentally detrimental acid mine drainage (AMD), the acidic nature and heavy-metal constituents of which may seriously contaminate soil as well as surface- and groundwater in various parts of the world. Thus, in order to improve industrial bioleaching and reduce the formation of AMD, a better understanding of the mechanisms involved is of crucial importance. The rate of bioleaching of metal sulfides is faster than that of chemical leaching $(19,22)$. In the case of pyrite bioleaching, the biotic leaching rate was previously reported to be 30-40-fold faster than that of abiotic leaching (19), which suggests that microbes use special processes to efficiently leach minerals.

Extensive efforts have been made to identify the mechanisms underlying bioleaching. It is now generally accepted that there are two modes of bioleaching of metal sulfides: "contact" and "non-contact" leaching $(20,23,30)$. In the case of pyrite leaching, non-contact leaching is mainly promoted by planktonic microbes, which oxidize the reduced Fe and $\mathrm{S}$

\footnotetext{
* Corresponding author. E-mail: mitsunobu.satoshi.dy@ehime-u.ac.jp;
} Tel: +81-89-946-9843; Fax: +81-89-946-9843. in solution. The resulting Fe(III) ions come into contact with a mineral surface and work as an oxidizing agent, which promotes mineral dissolution. Contact leaching is a process in which microbial cells attach to the mineral surface and promote mineral dissolution locally at the microbe-mineral interface. Previous studies showed that the extracellular polymeric substances (EPS) produced by leaching microbes are a key agent in the enhancement of mineral dissolution in contact leaching $(6,17)$. However, little is known of the role of microbial EPS in contact bioleaching, at the scale of 100 nanometers (1), because of difficulties with the direct chemical speciation of metals and biomolecules in EPS due to high spatial resolution in analyses. Although contact leaching has so far been mainly studied using indirect techniques, direct observations of the chemical speciation of metals and biomolecules is necessary for a better understanding of the mechanisms underlying contact leaching and bioleaching in general.

In the present study, we investigated the mechanisms underlying the contact leaching process in pyrite bioleaching using a direct chemical speciation technique, scanning transmission X-ray microscopy (STXM)-based near-edge X-ray absorption fine structure (NEXAFS) analysis. The STXM-based NEXAFS technique is a new powerful tool for researching microbe-mineral interactions. To date, there have been very few applications of the STXM technique to the study of bioleaching (16). The application of a STXM-based NEXAFS analysis, having high spatial resolution (less than $50 \mathrm{~nm}$ ) and allowing the direct detection of chemical species at high 
elemental specificities, will enable us to directly examine microbe-pyrite interface interactions.

\section{Materials and Methods}

\section{Bacterial strain and cultivation}

The acidophilic chemolithoautotrophic bacterium, Acidithiobacillus ferrooxidans, was used as the leaching microbe in the present study. $A$. ferrooxidans has been widely used in studies on industrial bioleaching and the formation of AMD $(9,22)$, and strain JCM7812 was used in this study. This strain, which was originally isolated from a sulfur and Fe sulfide mine in Japan, uses energy from the oxidation of reduced $\mathrm{Fe}$ and $\mathrm{S}$ for growth and fixes $\mathrm{CO}_{2}$ and $\mathrm{N}_{2}$ from the atmosphere (32). The strain was cultivated in mineral salt medium (Mackintosh medium) with Fe(II) sulfate immediately prior to pyrite bioleaching (12).

\section{Pyrite bioleaching with A. ferrooxidans.}

Pyrite bioleaching was performed in a batch process using pyrite powder. Natural pyrite from the Navajún mine, La Rioja, Spain was used (3). Cubic pyrite was ground and sieved to a particle size of $50-100 \mu \mathrm{m}$. Powdered pyrite was subsequently cleaned with boiled $6 \mathrm{M} \mathrm{HCl}$, rinsed with deionized water and acetone to remove $\mathrm{Fe}$ and $\mathrm{S}$ compounds, and dried at $120^{\circ} \mathrm{C}$ in an oven according to a previously developed procedure (24).

In pyrite bioleaching, $A$. ferrooxidans pre-cultured with $\mathrm{Fe}(\mathrm{II})$ sulfate was inoculated into $10 \mathrm{~mL}$ of Mackintosh medium with 5 $\mathrm{wt} \%$ pyrite (initial total cell number: $10^{8}$ cells $\mathrm{mL}^{-1}$ ). Cells were aerobically incubated at $30^{\circ} \mathrm{C}$ in a reciprocal shaker in the dark, as described by Mackintosh (12). The initial $\mathrm{pH}$ of the medium was adjusted to $\mathrm{pH} 3.0$ with $0.1 \mathrm{M} \mathrm{H}_{2} \mathrm{SO}_{4}$. The duration of the incubation was $35 \mathrm{~d}$ ( 5 weeks).

In order to determine the concentrations of total $\mathrm{Fe}, \mathrm{Fe}(\mathrm{II})$, total $\mathrm{S}$, sulfidic-S, and sulfate, the suspension samples were filtered through a $0.2-\mu \mathrm{m}$ PTFE filter (Advantec), and the filtrate was analyzed. Total Fe and S concentrations were determined by ICP-OES (Varian, 730-ES), and aqueous Fe(II) and sulfide concentrations by the phenanthroline technique and methylene-blue technique, respectively, using a spectrophotometer (27). The abundance of sulfate was measured by ion chromatography (Thermo Fisher Sci., ICS-5000plus).

The concentrations of cells in suspension were determined by fluorescent staining as previously described $(7,9)$. The samples used in cell counting were not applied to the STXM analysis. A 1-mL aliquot of the suspension was vacuum-filtered onto a black polycarbonate membrane filter (pore size $0.2 \mu \mathrm{m}$, Advantec). The cells collected were stained with Syto9 (Life Technologies) at a final concentration of $0.1 \mathrm{mM}$ for $10 \mathrm{~min}$. Imaging and counting were performed by epifluorescence microscopy (Olympus, BX-51) with a Canon X5 CCD camera. As described in a previous study (7), cells in 15-20 randomly distributed fields on the membrane filter were counted.

STXM-based C 1s, Fe 2p NEXAFS, and Fe K-edge XANES analyses

STXM analyses for $\mathrm{C} 1 \mathrm{~s}$ and Fe $2 \mathrm{p}$ NEXAFS were conducted at two STXM apparatuses installed in BL-13A at KEK-PF (Tsukuba) (26) and BL-4U at UVSOR (Okazaki) (18) in Japan. The theoretical spatial and spectral resolutions of both STXM apparatuses were less than $50 \mathrm{~nm}$ and $\pm 0.1 \mathrm{eV}$, respectively. STXM analyses were performed at room temperature (RT) and $\sim 1 / 6 \mathrm{~atm} \mathrm{He}$. Regarding sample preparation, $1 \mathrm{~mL}$ of suspension was transferred to a sterile plastic tube and washed gently three times with Fe-free Mackintosh medium ( $\mathrm{pH}$ 3.0) to remove excess salts. A small amount of the suspension was dropped onto a $\mathrm{Si}_{3} \mathrm{~N}_{4}$ membrane (Silson, thickness $100 \mathrm{~nm}$ ) and air-dried slowly at RT (10). All STXM data processing was carried out using the IDL package aXis2000 software (Hitchcook, an IDL-based analytical package, http://unicorn.mcmaster.ca/ aXis2000.html). A careful examination showed that there was no apparent photo alteration of $\mathrm{C}$ or Fe during the STXM analyses performed in the present study.
Iron K-edge X-ray absorption near edge structure (XANES) spectra were also measured in order to obtain information for bulk Fe species in solid samples. The analysis was performed at the beamlines BL01B1 at SPring-8 (Hyogo, Japan) and BL4A at KEK-PF (Tsukuba, Japan) with a Si(111) double-crystal monochromator and two mirrors. In the XANES analysis, a solid sample was collected by vacuum-filtration on a PTFE filter with a pore size of $0.2 \mu \mathrm{m}$ and freeze-dried. The solid collected was diluted to $c a$. $1 \mathrm{wt} \%$ with boron nitride and pelleted for the transmission detection mode for Fe XANES. The energy calibration for Fe XANES was performed using a pre-edge peak maximum of hematite at $7.113 \mathrm{keV}$. All XANES data processing was performed using the XAFS analysis package, REX2000 (Rigaku).

All model compounds for C NEXAFS such as albumin, sodium alginate, agarose, Escherichia coli DNA, and 1,2-dipalmitoyl-snglycero-3-phosphoethanolamine were obtained from a Japanese reagent provider, Wako Pure Chemicals. Natural biotite and siderite were obtained from the Japanese mineral provider, Hori Mineralogy as Fe NEXAFS and XANES model compounds. The secondary Fe minerals, ferrihydrite, goethite, and hematite were synthesized as described by Mitsunobu et al. (15). In addition, Fe(II) and Fe(III) complexed with organic ligands were synthesized as described by Mitsunobu et al. (15) and Chan et al. (4). Alginate was selected as a well-characterized acidic polysaccharide. Fe(II) (or Fe[III]) was added to sodium alginate as dissolved $\mathrm{Fe}$ (II) (or Fe[III]) chloride, in which $\mathrm{Fe}: \mathrm{COO}^{-}$was adjusted to $\sim 1: 100$. A small amount of the Fe-alginate suspension was dropped onto the $\mathrm{Si}_{3} \mathrm{~N}_{4}$ membrane and air-dried at RT prior to STXM measurements.

\section{SEM analysis}

The morphology of the pyrite surface was examined using scanning electron microscopy (SEM; Keyence VE-9800). A 1-mL suspension was taken and transferred to a $2-\mathrm{mL}$ sterile plastic tube. The supernatant solution was decanted, and an ethanol dehydration series of $50 \%, 70 \%, 90 \%$, and $100 \%(\mathrm{v} / \mathrm{v})$ was then performed immediately prior to the analysis. The sample was mounted on carbon tape, dried, and analyzed after osmium coating.

\section{Staining of extracellular polysaccharides with lectin}

The staining of extracellular polysaccharides of $A$. ferrooxidans was performed using a lectin technique as previously described by Mangold et al. (13). The technique has been used for the selective staining of EPS of A. ferrooxidans. A 1-mL suspension was transferred to a sterile plastic tube and washed gently twice with $1 \mathrm{~mL}$ of deionized water. Nucleic acids were then stained with Syto9 at a final concentration of $0.1 \mathrm{mM}$ for $10 \mathrm{~min}$. After one wash, EPS were stained for $30 \mathrm{~min}$ with Cy3-labeled Concanavalin A (ConA; Protein Mods) at a final concentration of $50 \mu \mathrm{g} \mathrm{mL}$. After two washes, the stained suspension was mounted on a glass slide or polycarbonate membrane filter. Imaging was performed by epifluorescence microscopy.

\section{Results and Discussion}

\section{Solution chemistry and SEM analysis}

Fig. 1 shows changes in aqueous Fe concentrations and cell numbers as a function of time with and without $A$. ferrooxidans. Total Fe concentrations and cell numbers both steadily increased throughout the incubation period. Fe concentrations were markedly higher in the presence of $A$. ferrooxidans rather than in its absence. The Fe(II) fraction was very low and less than $1 \%$ of the total Fe concentration throughout the incubation period. The positive correlation between cell numbers and aqueous Fe concentrations $\left(r^{2}=0.76\right)$ indicated that pyrite supported the growth of $A$. ferrooxidans and metabolic activity enhanced the leaching of pyrite. Although we also carried out 


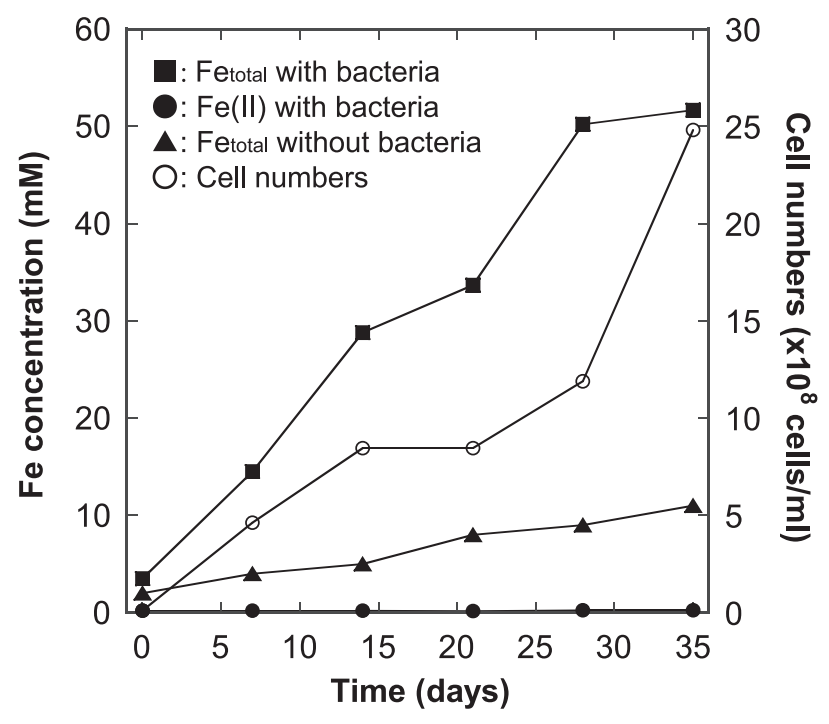

Fig. 1. Concentrations of total $\mathrm{Fe}$ and $\mathrm{Fe}(\mathrm{II})$ with/without bacteria and cell numbers. The initial amount of pyrite was $0.5 \mathrm{~g}$ in a total volume of $10 \mathrm{~mL}$ at an initial $\mathrm{pH} 3$.

measurements of sulfate concentrations (data not shown), no sulfidic $\mathrm{S}$ species, aqueous $\mathrm{H}_{2} \mathrm{~S}, \mathrm{HS}^{-}$, or $\mathrm{S}^{2-}$ ions, were detected during the incubation. Sulfate concentrations also increased with the incubation time, and the $\mathrm{S} / \mathrm{Fe}$ molar ratio at each time point was approximately $2(\mathrm{~S} / \mathrm{Fe}=1.7 \sim 2.1$, data not shown). $\mathrm{pH}$ gradually decreased over time due to the oxidation of pyrite and subsequent formation of sulfate acid, which was at approximately $\mathrm{pH} 2$ at the end of the incubation. These results suggest that most of the released $\mathrm{Fe}$ and $\mathrm{S}$ were left in the aqueous phase without significant mineral precipitation because the $\mathrm{S} / \mathrm{Fe}$ ratio in pyrite was theoretically 2 .

The surface morphology of pyrite incubated with/without bacteria for 4 weeks was investigated by SEM (Fig. 2). A large number of rod-shaped pits (black arrows in Fig. 2b, c, and d) were observed on the surface of pyrite incubated with the bacteria (white arrows), while no pits were observed on pyrite incubated without the bacteria, as shown in Fig. 2a. The sizes of these pits were similar to the size of $A$. ferrooxidans cells (Fig. 2b, c, and d). Previous studies have demonstrated that cell-sized pits are formed during the bioleaching of pyrite due to the contact leaching process, i.e., bioleaching by sessile microbes $(11,33)$. Thus, the appearance of pits on the surface of pyrite suggests that contact leaching occurred in the present pyrite bioleaching.

\section{STXM-based direct speciation of major biomolecules at the cell-pyrite interface}

SEM observations suggested the occurrence of contact leaching in this experiment. In order to investigate the mechanisms underlying the contact bioleaching process, we applied STXM-based C and Fe NEXAFS to pyrite samples after the bioleaching assay. By using the STXM-based NEXAFS technique, we were able to obtain direct information on the chemical species of $\mathrm{C}$ and $\mathrm{Fe}$ at the microbe-pyrite interface.

The STXM-based C images and C 1s NEXAFS spectra of A. ferrooxidans that attached to the pyrite particles (samples after a 2- and 4-week incubation) are shown in Fig. 3. The

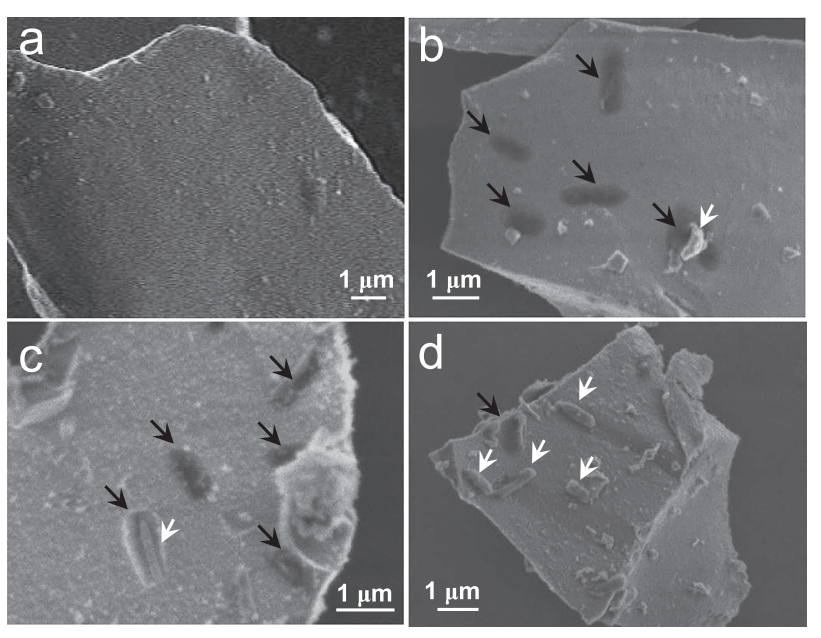

Fig. 2. SEM images of pyrite particles after a 4-week incubation without (a) and with A. ferrooxidans (b)-(d). Black and white arrows in images (b)-(d) stand for rod-shaped pits and A. ferrooxidans cells on the pyrite surface, respectively.

lower part of the $\mathrm{C}$ image in the 2-week sample shows a pyrite particle because the X-ray absorption of this area was saturated with an optical density of more than 2 (Fig. 3a). The spectral features of the model compounds in C NEXAFS showed clear differences among compounds representing polysaccharides, lipids, proteins, and nucleic acids (the functional group and transition corresponding to each peak are summarized in Table 1); therefore, we were able to distinguish major bacterial biomolecules using C NEXAFS. The spectrum of the whole cell area after a 2-week incubation consisted of peaks representing aromatic (I), aliphatic (II), amide (III), carboxyl (IV), and O-alkyl (V) C (whole cell in Fig. 3b). The spectral features of the whole cell were basically similar to those of a mixture of albumin, alginate, and lipids, exhibiting major peaks for aromatic at $285.2 \mathrm{eV}$ (I), aliphatic at $287.3 \mathrm{eV}$ (II), amide at $288.2 \mathrm{eV}$ (III), and carboxyl at $288.6 \mathrm{eV}$ (IV). In contrast, a significant difference was found in the C NEXAFS spectra of the cell-pyrite interface (Fig. 3b). The spectra of the interface (interfaces 1 and 2 in Fig. 3b) mainly included carboxyl (peak [IV]) and O-alkyl $\mathrm{C}$ (peak $[\mathrm{V}]$ ), typical of acidic and neutral polysaccharides, whereas aromatic (I), aliphatic (II), and amide (III) peaks were smaller than those of the whole cell. A similar localization of polysaccharides was also observed in our preliminary study (16). In addition, the attached $A$. ferrooxidans cells after the 2- and 4-week incubations were successfully stained by the lectin specific for polysaccharides (Fig. 4a and b), indicating that the $A$. ferrooxidans cells that attached to pyrite were coated with polysaccharide-rich EPS (2). Hence, the spectroscopic results from C NEXAFS were consistent with those of the lectin staining analysis. Thus, these results consistently suggest that $A$. ferrooxidans abundantly produces EPS in the polysaccharides on the pyrite surface.

Previous studies based on the characterization of extracted EPS found that the chemical constituents of EPS produced by $A$. ferrooxidans varied depending on the type of growth substrate (e.g. pyrite and elemental S). The EPS of $A$. ferrooxidans grown on pyrite contain markedly more uronic acid residues 

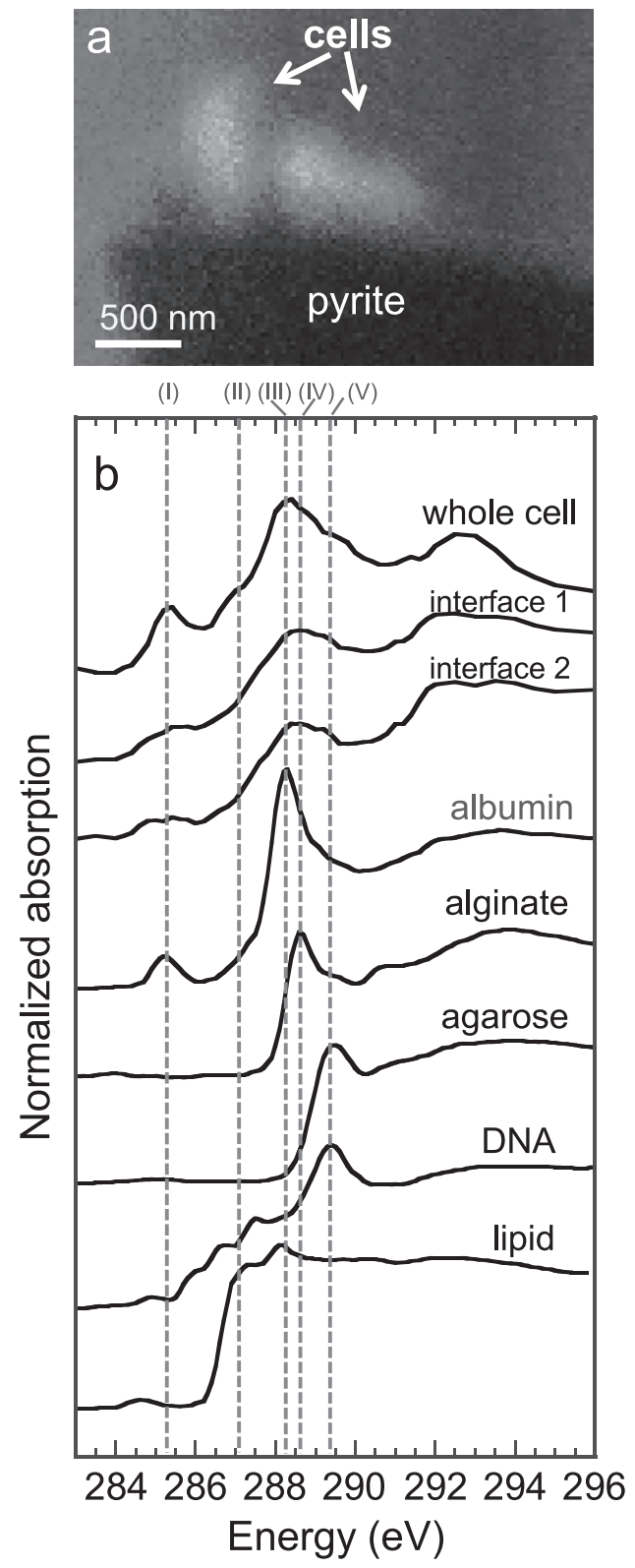

Fig. 3. (a) STXM-based $\mathrm{C}$ image of sessile A. ferrooxidans cells on pyrite in the 2-week incubation. The image was obtained by dividing the two images at $282 \mathrm{eV}$ (C 1s pre-edge energy) and $304 \mathrm{eV}$ (post-edge energy). (b) STXM-based C 1s NEXAFS spectra of model compounds and sessile $A$. ferrooxidans cells. In C NEXAFS, sodium alginate (acidic polysaccharide), agarose (neutral polysaccharide), albumin (protein), Escherichia coli DNA (nucleic acid), and 1,2-dipalmitoyl-sn-glycero-3phosphoethanolamine (lipid) were selected as model compounds for major microbial biomolecules, as in previous studies $(5,8)$. The dotted lines $(\mathrm{I})$ to $(\mathrm{V})$ in Fig. 3b stand for the peak energies of the major organic functional groups present in the model compounds shown in Table 1.

Table 1. Major organic functional groups present in model compounds and samples (summarized data from Chan et al. (5) and Keiluweit et al. (8))

\begin{tabular}{cccl}
\hline peak & Energy (eV) & Transition & Functional group \\
\hline (I) & 285.2 & $1 \mathrm{~s} \rightarrow \pi^{*} \mathrm{C}=\mathrm{C}$ & aromatic C \\
(II) & 287.3 & $1 \mathrm{~s} \rightarrow 3 \mathrm{p} / \sigma^{*}$ & aliphatic C \\
(III) & 288.2 & $1 \mathrm{~s} \rightarrow \pi^{*}{ }_{\mathrm{C}=\mathrm{O}}$ & amide C (peptide bond) \\
(IV) & 288.6 & $1 \mathrm{~s} \rightarrow \pi^{*}=\mathrm{C}=$ & carboxyl C (acidic polysaccharide) \\
(V) & 289.3 & $1 \mathrm{~s} \rightarrow 3 \mathrm{p} / \sigma^{*}$ & O-alkyl C \\
\hline
\end{tabular}

(a) 2 weeks
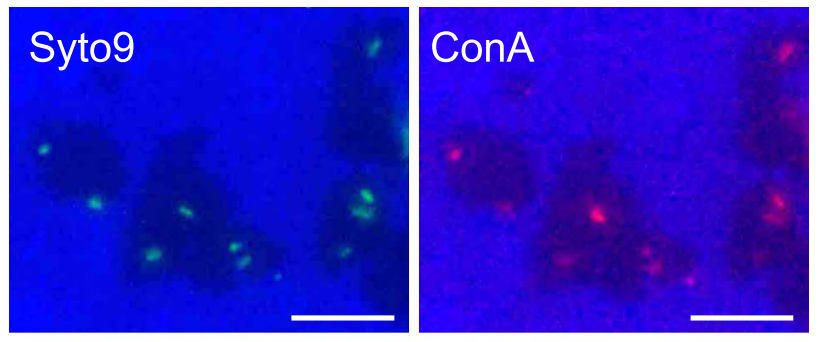

(b) 4 weeks
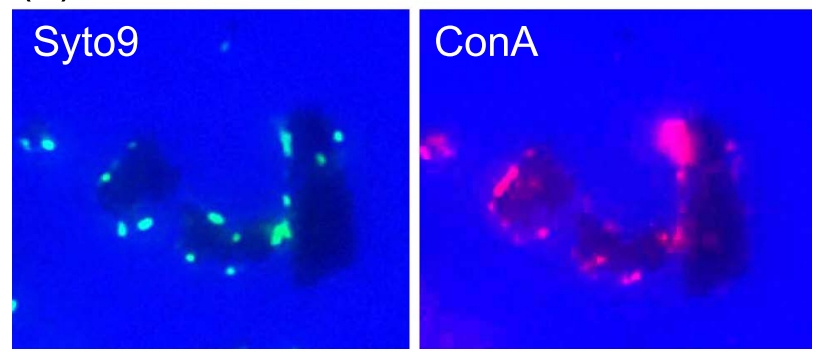

Fig. 4. Sessile A. ferrooxidans cells on pyrite particles stained with Syto9 for nucleic acids, and with ConA for extracellular polysaccharides after incubations for 2 weeks (a) and 4 weeks (b). Black grains in the images show pyrite particles. All scale bars: $10 \mu \mathrm{m}$.

and neutral sugars, but fewer fatty acids than EPS from cells grown on elemental $\mathrm{S}(6,31)$. This is consistent with our results showing the high composition of acidic polysaccharides in EPS on the pyrite surface.

\section{STXM-based direct speciation of Fe at the cell-pyrite interface}

We investigated the Fe species in EPS produced at the cell-pyrite interface by the Fe NEXAFS analysis. Fig. 5 shows STXM-based Fe and $\mathrm{C}$ images and Fe NEXAFS of $A$. ferrooxidans attached to pyrite particles in the 2-week incubation of samples. The image in Fig. 5c shows that Fe was localized around the surface of the A. ferrooxidans cells. C NEXAFS demonstrated the appearance of a polysaccharide-rich layer at the cell-pyrite interface, suggesting that Fe had accumulated in this polysaccharide layer. The Fe NEXAFS spectra of samples and model compounds are shown in Fig. 5d. The absorption edge of Fe(II) species shifted to a lower energy than that of $\mathrm{Fe}(\mathrm{III})$ species, as described in a previous study (28). The vertical lines in Fig. 5d show the edge peaks characteristic for Fe(II) (707.5 eV) and Fe(III) (709.1 eV), respectively, indicating that, as reported in previous studies $(25,28)$, the abundances of $\mathrm{Fe}(\mathrm{II})$ and $\mathrm{Fe}(\mathrm{III})$ may be estimated using these specific peaks. The spectra of the whole cell and cell-pyrite interface both consisted of Fe(II) and Fe(III) peaks, and no clear difference was found between these spectra. Thus, the Fe species in the cell and interface were both uniformly $\mathrm{Fe}(\mathrm{II}) / \mathrm{Fe}$ (III) mixed species. The $\mathrm{Fe}$ species found in the cell grown on pyrite may have resulted from (i) $\mathrm{Fe}$ in aqueous solution, (ii) $\mathrm{Fe}$ complexed with ligands, and (iii) $\mathrm{Fe}$ in precipitates having a smaller particle size than the spatial resolution of STXM $(50 \mathrm{~nm})$. Regarding (i), we may exclude dissolved $\mathrm{Fe}$ in the leaching solution because most $\mathrm{Fe}$ in the leaching solution was $\mathrm{Fe}(\mathrm{III})$ and the $\mathrm{Fe}(\mathrm{II})$ fraction was less than 1\%, as shown in Fig. 1. We may 

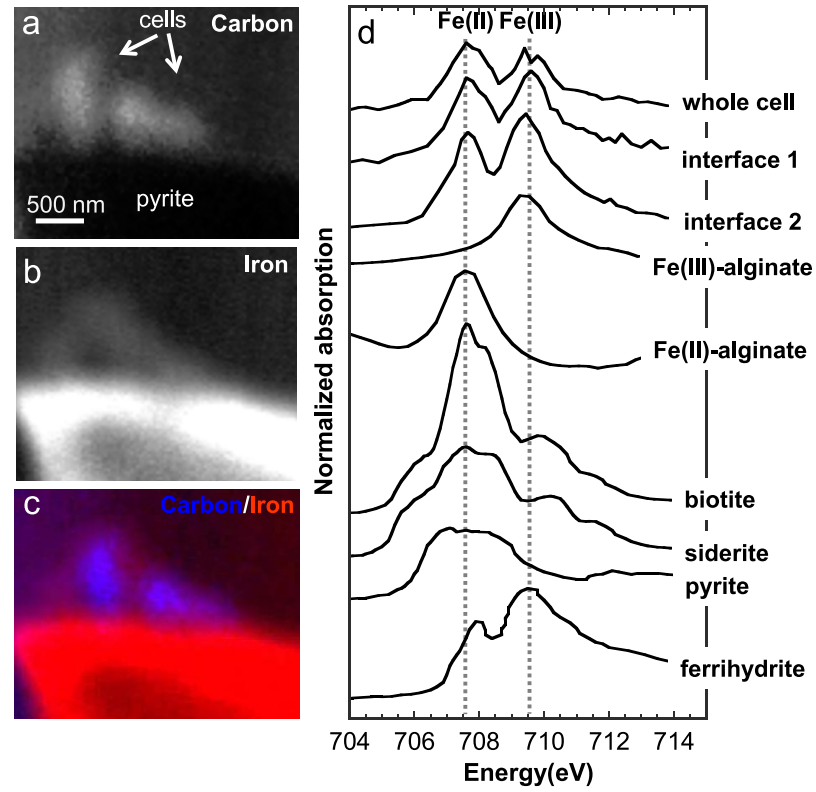

Fig. 5. STXM-based $\mathrm{C}, \mathrm{Fe}$, and merged images (a, b, c) and Fe $2 \mathrm{p}$ NEXAFS spectra (d) of model compounds and sessile $A$. ferrooxidans cells on pyrite after a 2-week incubation. Pyrite, ferrihydrite, siderite, biotite, and $\mathrm{Fe}$ (II) and $\mathrm{Fe}(\mathrm{III})$ complexed with acidic polysaccharides (sodium alginate) were selected as the model compounds for $\mathrm{Fe}$ NEXAFS. Vertical lines in Fig. 5d were displayed to show the specific $\mathrm{Fe}(\mathrm{II})$ and $\mathrm{Fe}(\mathrm{III})$ peaks at 707.5 and $709.1 \mathrm{eV}$, respectively. The $\mathrm{Fe}$ image was obtained by dividing two images at $700 \mathrm{eV}$ (Fe 2p pre-edge energy) and $730 \mathrm{eV}$ (post-edge energy).

also rule out dissolved $\mathrm{Fe}$ in the bacterial cell cytoplasm because the concentration needs to approach $0.1 \mathrm{mM}$ in order to be detected by STXM-NEXAFS (28). The Fe concentration in the bacterial cell cytoplasm is generally less than $0.5 \mu \mathrm{M}$ (14). Regarding (iii), we may also rule out nanoparticulate precipitates on the basis of the Fe NEXAFS spectra because the spectral features of $\mathrm{Fe}(\mathrm{II})$ and $\mathrm{Fe}(\mathrm{III})$ in the sample did not match those of $\mathrm{Fe}(\mathrm{II})$-bearing sulfide, carbonate, or silicate minerals (Fig. 5d). In contrast, the spectral features of Fe in the sample were similar to those of $\mathrm{Fe}$ (II) and Fe(III) complexed by acidic polysaccharides in model compounds. In addition, the Fe image showed the accumulation of Fe in EPS at the pyrite surface (Fig. 5c). These results are consistent with a chemical association between $\mathrm{Fe}$ and $\mathrm{C}$ through the complexation of $\mathrm{Fe}$ by organic functional groups involved in EPS, case (ii). Previous studies also suggested based on stoichiometric estimations that $\mathrm{Fe}$ is complexed with organic ligands in EPS $(6,30)$, which is consistent with our results.

The bulk Fe K-edge XANES analysis with quantitative fitting showed that the bulk Fe species in the solids was mainly pyrite over the incubation period and prominent amounts of other Fe species were not found (Fig. 6), indicating that the $\mathrm{Fe}(\mathrm{II}) / \mathrm{Fe}(\mathrm{III})$ mixed species was the $\mathrm{Fe}$ species observed locally at the cell-pyrite interface.

Implication of Fe(II) detection in the interfacial EPS for the bioleaching mechanism

Nanoscale $\mathrm{C}$ and Fe NEXAFS analyses showed that the interfacial EPS contain significant amounts of $\mathrm{Fe}(\mathrm{II})$ in addition to $\mathrm{Fe}(\mathrm{III})$ in the sessile cell on pyrite. A plausible candi-

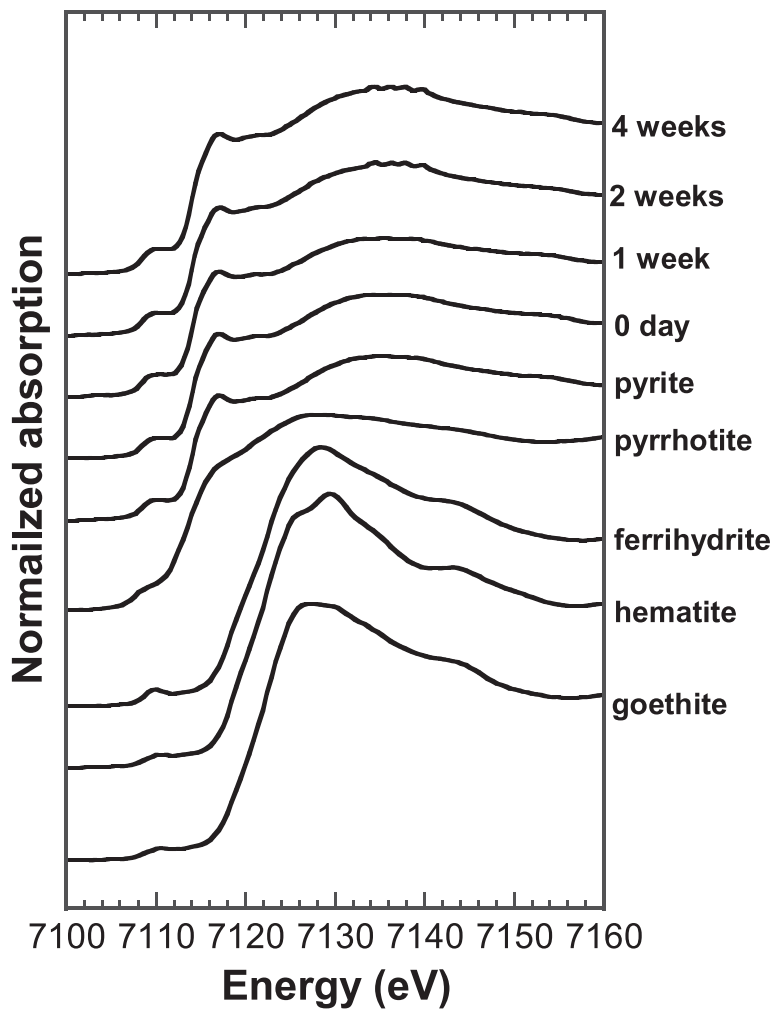

Fig. 6. Iron K-edge XANES spectra of bulk solid samples after incubations and $\mathrm{Fe}$ model compounds of pyrite, pyrrhotite, ferrihydrite, hematite, and goethite.

date for the $\mathrm{Fe}$ (II) and $\mathrm{Fe}(\mathrm{III})$ species was the complex with organic ligands in EPS. A noteworthy result was the detection of $\mathrm{Fe}(\mathrm{II})$ in the interfacial EPS. To the best of our knowledge, this is the first detection of $\mathrm{Fe}(\mathrm{II})$ in the EPS produced by bioleaching microbes.

A probable explanation for the $\mathrm{Fe}(\mathrm{II})$ detected is the leaching of $\mathrm{Fe}$ (II) from pyrite. The EPS of pyrite-grown $A$. ferrooxidans contain acidic polysaccharides with a carboxylic group, such as uronic acid residues (6). Organic ligands such as carboxylic groups generally increase metal solubility by complexing the metal (30), and the complexed Fe(II) has a higher bioavailability than solid $\mathrm{Fe}(\mathrm{II})$. A second possibility for the $\mathrm{Fe}$ (II) detected is the formation of $\mathrm{Fe}$ (II) by the oxidation of sulfides at the cell-pyrite interface. As stated above, A. ferrooxidans has the ability to change the chemical constituents in EPS, depending on the type of substrate to improve cell attachment to the substrate (6). The EPS of A. ferrooxidans grown on pyrite contained more uronic acid residues and complexed $\mathrm{Fe}(\mathrm{III})$ (12) than that of $A$. ferrooxidans growing on elemental $\mathrm{S}$ and in $\mathrm{Fe}(\mathrm{II})$ sulfate solution. The complexation of uronic acid with $\mathrm{Fe}(\mathrm{III})$ allows cells to have a net positive charge (6, 22 ), which means that they may preferentially attach to negatively charged pyrite by electrostatic interactions, thereby promoting the dissolution of pyrite. Researchers have also suggested another role for Fe(III) in EPS: an oxidizing agent for sulfides $(21,22)$; i.e., the Fe(III) in EPS may abiotically oxidize sulfides in pyrite to thiosulfate and sulfate according to equations 1 and 2.

$$
\begin{aligned}
& \mathrm{FeS}_{2}+6 \mathrm{Fe}^{3+}+3 \mathrm{H}_{2} \mathrm{O} \rightarrow \mathrm{S}_{2} \mathrm{O}_{3}{ }^{2-}+7 \mathrm{Fe}^{2+}+6 \mathrm{H}^{+} \\
& \mathrm{S}_{2} \mathrm{O}_{3}{ }^{2-}+8 \mathrm{Fe}^{3+}+5 \mathrm{H}_{2} \mathrm{O} \rightarrow 2 \mathrm{SO}_{4}^{2-}+8 \mathrm{Fe}^{2+}+10 \mathrm{H}^{+}
\end{aligned}
$$


However, this interfacial process is merely speculative because no Fe(II) in EPS subsequently formed by this oxidation process has been observed to date. Previous studies determined the Fe species in EPS by indirect methods including EPS extraction and digestion, which may cause some unwanted oxidation of the Fe species during the analysis. The Fe(II) detected by our direct speciation technique, STXM-based NEXAFS, is a possible indication supporting the oxidative attack by Fe(III) in EPS, while knowledge of the nature of the $\mathrm{S}$ species in interfacial EPS is necessary in order to allow a more detailed discussion of this process.

In summary, this study investigated the nanoscale spatial distribution of major biomolecules such as proteins, polysaccharides, lipids, and nucleic acids as well as Fe species at the cell-pyrite interface during pyrite bioleaching by $A$. ferrooxidans using STXM-based $\mathrm{C}$ and Fe NEXAFS analyses. The $\mathrm{C}$ NEXAFS analyses directly showed that a polysaccharide-rich layer was localized at the cell-pyrite interface, indicating the production of polysaccharide-rich EPS by sessile $A$. ferrooxidans. Furthermore, combined with the Fe NEXAFS analysis, we detected $\mathrm{Fe}$ (II) in the interfacial EPS at the cell-pyrite interface. The detection of $\mathrm{Fe}(\mathrm{II})$ is a possible indication showing that $\mathrm{Fe}$ (III) in EPS functions as an oxidizing agent for the sulfides in pyrite at the cell-pyrite interface. Our results indicate that Fe(III) in EPS, as well as its previously reported role in the electrostatic attachment of cells to pyrite, is a key component enhancing pyrite dissolution. Thus, our results provide important information for understanding the mechanisms underlying bacterial mineral leaching and the formation of AMD.

\section{Acknowledgements}

This work was partly supported by funds from the University of Shizuoka and JSPS Grant-in-Aid for Challenging Exploratory Research (Grant No. 25610164). The synchrotron experiments were performed with the approval of JASRI (Proposal Nos. 2012B1386, 2014A1493, and 2014B1267), KEK (Proposal Nos. 2012G640, 2013S2-003, 2014G617), and UVSOR (Proposal No. S-13-MS-1005).

\section{References}

1. Becker, T., N. Gorham, D.W. Shiers, and H.R. Watling. 2011. In situ imaging of Sulfobacillus thermosulfidooxidans on pyrite under conditions of variable $\mathrm{pH}$ using tapping mode atomic force microscopy. Process Biochem. 46:966-976.

2. Bellenberg, S., C.F. Leon-Morales, W. Sand, and M. Vera. 2012. Visualization of capsular polysaccharide induction in Acidithiobacillus ferrooxidans. Hydrometallurgy 129-130:82-89.

3. Calvo, M., and E. Sevillano. 1989. Famous mineral localities: pyrite crystals from Soria and La Rioja provinces, Spain. Mineralogical Record 20:451-456.

4. Chan, C.S., F.C. Sirine, D.C. Edwards, D. Emerson, and J.F. Banfield. 2009. Iron oxyhydroxides mineralization on microbial extracellular polysaccharides. Geochim. Cosmochim. Acta 73:3807-3818.

5. Chan, C.S., S.C. Fakra, D. Emerson, E.J. Fleming, and K.J. Edwards. 2011. Lithotrophic iron-oxidizing bacteria produce organic stalks to control mineral growth: implication for biosignature formation. ISME J. 5:717-727.

6. Gehrke, T., J. Telegdi, D. Thierry, and W. Sand. 1998. Importance of extracellular polymeric substances from Thiobacillus ferrooxidans for bioleaching. Appl. Environ. Microbiol. 64:2743-2747.

7. Hao, J., R. Murphy, E. Lim, M.A.A. Schoonen, and D.R. Strongin. 2009. Effects of phospholipid on pyrite oxidation in the presence of autotrophic and heterotrophic bacteria. Geochim. Cosmochim. Acta 73:4111-4123.
8. Keiluweit, M., J.J. Bougoure, L.H. Zeglin, D.D. Myrold, P.K. Weber, J. Pett-Ridge, M. Kleber, and P. Nico. 2012. Nano-scale investigation of the association of microbial nitrogen residues with iron(hydr)oxides in a forest soil O-horizon. Geochim. Cosmochim. Acta 95:213-226.

9. Kinzler, K., T. Gehrke, J. Telegdi, and W. Sand. 2003. Bioleaching-a result of interfacial processes caused by extracellular polymeric substances (EPS). Hydrometallurgy 71:83-88.

10. Lawrence, J.R., G.D.W. Swerhone, G.G. Leppard, T. Araki, X. Zhang, M.M. West, and A.P. Hitchcock. 2003. Scanning transmission X-ray, laser scanning, and transmission electron microscopy mapping of the exopolymeric matrix of microbial biofilms. Appl. Environ. Microbiol. 69:5543-5554.

11. Liu, H., G. Gu, and Y. Xu. 2011. Surface properties of pyrite in the course of bioleaching by pure culture of Acidithiobacillus thioooxidans. Hydrometallurgy 108:143-148.

12. Mackintosh, M. 1978. Nitrogen fixation by Thiobacillus ferrooxidans. J. Gen. Microbiol. 105:215-218.

13. Mangold, S., M. Laxander, K. Harneit, T. Rowwerder, G. Claus, and W. Sand. 2008. Visualization of Acidithiobacillus ferrooxidans biofilms on pyrite by atomic force and epifluorescence microscopy under various experimental conditions. Hydrometallurgy 94:127-132.

14. Martinez, J.L., A. Delgado-Iribarren, and F. Baquero. 1990. Mechanisms of iron acquisition and bacterial virulence. FEMS Microbiol. Lett. 75:45-56.

15. Mitsunobu, S., F. Shiraishi, H. Makita, B.N. Orcutt, S. Kikuchi, B.B. Jorgensen, and Y. Takahashi. 2012. Bacteriogenic Fe(III) (oxyhydr) oxides characterized by synchrotron microprobe coupled with spatially resolved phylogenetic analysis. Environ. Sci. Technol. 46:3304-3311.

16. Mitsunobu, S., M. Zhu, Y. Takeichi, T. Ohigashi, H. Suga, H. Makita, M. Sakata, K. Ono, K. Mase, and Y. Takahashi. 2015. Nanoscale identification of extracellular organic substances at the microbemineral interface by scanning transmission X-ray microscopy. Chem. Lett. 44:91-93.

17. Nöel, N., B. Florian, and W. Sand. 2010. AFM \& EFM study on attachment of acidophilic leaching organisms. Hydrometallurgy 104:370-375.

18. Ohigashi, T., H. Arai, T. Araki, N. Kondo, E. Shigemasa, A. Ito, N. Kosugi, and M. Katoh. 2013. Construction of the scanning transmission X-ray microscope beamline at UVSOR. J. Physics Conf. Series 463:012006.

19. Olson, G.J. 1991. Rate of pyrite bioleaching by Thiobacillus ferrooxidans: results of an interlaboratory comparison. Appl. Environ. Microbiol. 57:642-644.

20. Rawlings, D.E. 2002. Heavy metal mining using microbes. Annu. Rev. Microbiol. 56:65-91.

21. Rohwerder, T., T. Gehrke, K. Kizler, and W. Sand. 2003. Bioleaching review part A: progress in bioleaching: fundamentals and mechanisms of bacterial metal sulfide oxidation. Appl. Microbiol. Biotechnol. 63:239-248.

22. Sand, W., and T. Gehrke. 2006. Extracellular polymeric substances mediate bioleaching/biocorrosion via interfacial processes involving iron(III) ions and acidophilic bacteria. Res. Microbiology 157:49-56.

23. Sand, W., T. Gherke, P.G. Jozsa, and A. Schippers. 2001. (Bio)chemistry of bacterial leaching-direct vs indirect bioleaching. Hydrometallurgy 59:159-175.

24. Schippers, A., P.G. Jozsa, and W. Sand. 1996. Sulfur chemistry in bacterial leaching of pyrite. Appl. Environ. Microbiol. 62:3424-3431.

25. Stodolna, J., Z. Gainsforth, H. Leroux, A.L. Butterworth, T. Tyliszczak, D. Jacob, and A.J. Westphal. 2013. Iron valence state of fine-grained material from the Jupiter family comet $81 \mathrm{P} /$ Wild 2 -A coordinated TEM/STEM EDS/STXM study. Geochim. Cosmochim. Acta 122:116.

26. Takeichi, Y., N. Inami, H. Suga, K. Ono, and Y. Takahashi. 2014. Development of a compact scanning transmission X-ray microscope at the Photon Factory. Chem. Lett. 43:373-375.

27. The Japan Society for Analytical Chemistry, Hokkaido Branch. 2005. p. 216-219 \& 280-283. In Mizu no Bunseki (Water Research) 5th ed., Kagakudojin, Kyoto (in Japanese).

28. Toner, B.M., S.C. Fakra, S.J. Manganini, C.M. Santelli, M.A. Marcus, J.W. Moffett, O. Rouxel, C.R. German, and K.J. Edwards. 2009. Preservation of iron(II) by carbon-rich matrices in a hydrothermal plume. Nature Geosci. 2:197-201.

29. Tributsch, H. 2001. Direct versus indirect bioleaching. Hydrometallurgy 59:177-185. 
30. Vera, M., A. Schippers, and W. Sand. 2013. Progress in bioleaching: fundamentals and mechanisms of bacterial metal sulfide oxidationpart A. Appl. Microbiol. Biotechnol. 97:7529-7541.

31. Vu, B., M. Chen, R.J. Crawfold, and E.P. Ivanova. 2009. Bacterial extracellular polysaccharides involved in biofilm formation. Molecules $14: 2535-2554$.
32. Wakao, N., K. Hanada, A. Takahashi, Y. Sakurai, and H. Shiota. 1991 Morphological, physiological, and chemotaxonomical characteristics of iron- and sulfur-oxidizing bacteria isolated from acid mine drainage waters. J. Gen. Appl. Microbiol. 37:35-48.

33. Zhu, T., X. Lu, H. Liu, J. Li, X. Zhu, J. Lu, and R. Wang. 2014. Quantitative X-ray photoelectron spectroscopy-based depth profiling of bioleached arsenopyrite surface by Acidithiobacillus ferrooxidans. Geochim. Cosmochim. Acta 127:120-139. 